\title{
O direito fundamental à cultura manifestado por meio da sociedade em rede durante a pandemia da COVID-19
}

\section{The fundamental right to culture manifested through the network society during the COVID-19 pandemic}

\author{
Jefferson Lopes Custódio ${ }^{1 *}$, Fernanda Linhares Silva², Onnara Custódio Gomes ${ }^{3}$, Lívia \\ Lopes Custódio ${ }^{4}$
}

\begin{abstract}
RESUMO
O surgimento da crise sanitária no mundo, provocada pelo vírus Sars-Cov-2, impactou abruptamente a humanidade e modificou alguns hábitos das pessoas. Assim, o isolamento social estimulou a utilização de plataformas virtuais e, nessa perspectiva, a sociedade em rede, construída no bojo de uma teia digital, assumiu um papel relevante nas variadas formas de expressão artístico-cultural. Diante disso, propõe-se um diálogo acerca da arte e da cultura expressadas pela sociedade informacional através da rede mundial de computadores, durante a fase pandêmica. Para tanto, parte-se da hipótese de que o direito fundamental à cultura pode ser manifestado através da referida sociedade de informação, que é constituída por usuários conectados à internet. Trata-se de pesquisa bibliográfica, teórica e documental, com abordagem qualitativa, referenciada em obras, jornais, revistas, produções acadêmicas, normas legais e dados secundários. Em sede de resultado, espera-se motivar um debate sobre as multifacetadas atividades artístico-culturais que a sociedade em rede proporciona ao seu público virtual, que visam promover a cultura e remediar as dificuldades enfrentadas durante a COVID-19.
\end{abstract}

Palavras-chave: Arte e cultura digital; Direito fundamental; Sociedade em rede; COVID-19.

\begin{abstract}
The emergence of the health crisis in the world, caused by the Sars-Cov-2 virus, abruptly impacted humanity and changed some people's habits. Thus, social isolation encouraged the use of virtual platforms and, from this perspective, the network society, built in the midst of a digital web, plays a relevant role in the various forms of artistic-cultural expression. Therefore, it is proposed a dialogue about art and culture expressed by the information society through the world wide web, during the pandemic phase. For that, it starts from the hypothesis that the fundamental right to culture can be manifested through the referred information society, which is constituted, without distinction, by users connected to the internet. It is a bibliographical, theoretical and documentary research, with a qualitative approach, referenced in works, newspapers, magazines, academic productions, legal norms and secondary data. As a result, it is expected to encourage a debate on the multifaceted artistic and cultural activities that the network society provides to its virtual audience, which aim to promote culture and remedy the difficulties faced during COVID-19.
\end{abstract}

Keywords: Digital art and culture; Fundamental right; Network society; COVID-19.

\footnotetext{
${ }^{1}$ Universidade de Fortaleza (UNIFOR).*E-mail: jeffersonlopescustodio@gmail.com.

${ }^{2}$ Universidade Anhanguera. E-mail: advfernandalinhares@gmail.com.

${ }^{3}$ Universidade Estadual Paulista (UNESP). E-mail: Onnara.custodio@unesp.br.

${ }^{4}$ Universidade Estadual do Ceará. E-mail: liviacustodio@yahoo.com.br.
} 


\section{INTRODUÇÃO}

A COVID-19, provocada pelo vírus Sars-Cov-2, já é considerada uma das maiores crises da história mundial, não apenas pelas milhares de mortes e suas consequências sanitárias, mas também pelo seu potencial maléfico provocado em outras áreas, como o aumento de depressão no planeta, queda anual de quase $10 \%$ na produção global, recrudescimento do desemprego mundial, o aumento da pobreza no planeta, dentre outros prejuízos causados nos setores da educação, comércio e segurança pública (CHADE, 2020).

Nesse ritmo, a inesperada mudança no cotidiano da população mundial, em razão da quarentena introduzida pelo coronavírus, impactou drasticamente a vida de diversos segmentos da sociedade, aprisionando o homem e transformando o mundo virtual em refúgio contra as medidas restritivas, impostas de um modo a cercear algumas garantias fundamentais da pessoa humana, em benefício de um bem jurídico que mereceu uma tutela especial na ordem constitucional vigente: o direito à vida.

Com efeito, se por um lado se trata de uma crise mundial de saúde com proporções preocupantes, durante a qual se adotou medidas extremas contra o convívio social; noutra banda, a população mundial dispõe de ferramentas tecnológicas, graças ao avanço científico da nova era da informação, de maneira que os ambientes virtuais se transformaram em opção para os que pretendem manter seus relacionamentos pessoais, sociais e profissionais, bem como consumirem bens culturais e se manifestarem artística e culturalmente.

Nesse domínio de ideias, conveniente evidenciar a emergência da sociedade em rede, ou sociedade de informação, ou sociedade informacional, construída a partir de plataformas virtuais, de modo a revelar a importância e a influência da mídia digital sobre a vida das pessoas, notadamente no plano artístico-cultural. Cuida-se de uma geração de pessoas concebida a partir de mecanismos eletrônicos e que vem formatando a manifestação individual ou de grupos sociais.

Para Manuel Castells, um dos pioneiros no uso da expressão, a sociedade em rede representa uma espécie de sociabilidade fundada numa dimensão virtual, que promove a formação da cultura de virtualidade real, cuja comunidade é impulsionada pelo ciberespaço e que se compõe graças às novas tecnologias do mundo contemporâneo, de modo que transcendem questões de espaço e de tempo (CASTELLIS, 2002). O grande 
desafio, entretanto, é inserir no seleto grupo digital os desassistidos, assim entendidos aqueles que ainda permanecem conectados tão-somente à vida real, excluídos do ambiente digital.

Assim, o recorte proposto neste trabalho está abalizado na ideia da manifestação artística e cultural por meio da web, com fundamento na liberdade de expressão, traduzida no direito fundamental à cultura, bem jurídico agasalhado pela Carta Magna de 1988, por meio do artigo 215 da Constituição Federal de 1988 (BRASIL, 2018).

Com base no comando constitucional, oportuno ponderar sobre arte e cultura, de logo cabendo o registro que ambas se relacionam e se retroalimentam de forma estreita. No caso, conceituar a primeira é tarefa difícil, mas Leon Tolstoi encontrou uma fórmula para demonstrar que a arte não é somente um objeto de prazer estético, mas sobretudo um meio de intercâmbio que introduz sentimento benéfico a um pessoa (TOLSTOI, 2002).

Em outra ocasião, o autor russo sublinha que a arte não é encontrada apenas nas exposições, teatros, obras, monumentos e eventos em geral, mas ela é perceptível até na maneira de falar e de se vestir, numa decoração de casa e até mesmo em conversas e piadas, de forma que não é caracterizada apenas de maneira bela e formal (TOLSTOI, 2011). E, por óbvio, pode ser expressada de maneira virtual.

Sobre o termo cultura, Cunha Filho (2018) singulariza que a sua etimologia é encontrada na língua latina, extraída do verbo colère, e sempre foi utilizada pelas civilizações antigas, possuindo diversos significados na contemporaneidade ${ }^{5}$, muito embora o professor de direitos culturais a delineou, no campo jurídico, como uma produção humana vinculada ao ideal de aprimoramento e que visa à dignidade da espécie, considerada de modo geral ou individual (CUNHA FILHO, 2018).

Desse modo, é crível ponderar que, presencial ou remotamente, as manifestações artístico-culturais devem exprimir valores relacionados à liberdade, à arte, à memória, ao fluxo de saberes e à identidade de uma pessoa, ou mesmo de um determinado grupo social, incluindo as minorias desamparadas: como índios, mulheres, negros, LGBTQ+, portadores de necessidades especiais, dentre outros.

E todas as manifestações do indivíduo são garantidas pela Lei Maior, tão verdade que a Constituição Cidadã de 1988 erigiu a livre manifestação da atividade artística como direito fundamental, conforme preceituado no seu artigo $5^{\circ}$, inciso IX (BRASIL, 2018).

\footnotetext{
${ }^{5} \mathrm{O}$ termo cultura assume milhares de significados, até porque não é matéria circunscrita à antropologia e à filosofia, bem assim está nas ruas, na boca do povo (GOMES, 2014).
} 
Acresça-se, no entanto, que o ordenamento jurídico brasileiro não protege as manifestações que atentam contra a liberdade humana, a moral e os bons costumes.

Em complemento, embora importante e necessária à formação e socialização humana, não se deve ignorar que as manifestações artístico-culturais não conferem um direito fundamental ilimitado, vedando-se os abusos e os atos violentos, mesmo praticados por trás de uma tela de computador, que desbordem do verdadeiro espírito de expressar pacificamente a criatividade humana, os modos de vida, os valores, as tradições e as crenças de um determinado povo.

No plano normativo, pertinente trazer à colação o Decreto $\mathrm{n}^{\circ} 6.177 / 2007$ (BRASIL, 2007), que promulgou internamente a Convenção sobre a Proteção e Promoção da Diversidade das Expressões Culturais, assinada em Paris, no ano de 2005, ocasião em dispôs que as manifestações das pessoas devem ser transmitidas intra e extra grupos sociais. Assim, por meio da arte, o cidadão pode e deve participar da vida cultural da comunidade em que vive ou, até mesmo, compartilhar conhecimentos com outros agrupamentos humanos, de forma virtual.

No mesmo sentido, a Lei $\mathrm{n}^{\mathrm{o}}$ 12.965/2014 (BRASIL, 2014), que inaugurou o marco civil da internet no país, estabeleceu regras para o meio ambiente digital na sociedade em rede, bem assim impôs um regime jurídico para o uso da internet, edificando como fundamentos: a liberdade de expressão, a pluralidade, a diversidade e a finalidade social da rede.

E o comando legal retro é compatível com a orientação constitucional materializada no artigo $5^{\circ}$ da Lei Maior, inciso IV, no sentido de que "é livre a manifestação do pensamento, sendo vedado o anonimato" (BRASIL, 2018), que tem status de direito fundamental e visa à garantia do exercício da cidadania cultural por meio da liberdade de expressão da atividade intelectual, artística, científica e de comunicação.

Além disso, pertinente registrar a disposição do $\S 3^{\circ}$, do artigo 215 da $\mathrm{CF} / 88$, o qual estabelece que a lei criará o Plano Nacional de Cultura, com vistas ao desenvolvimento cultural do país e à integração das ações do poder público, enumerando algumas diretrizes, dentre as quais: defender e valorizar o patrimônio cultural brasileiro, bem como produzir, promover e difundir os bens culturais (BRASIL, 2018). Na sequência, o legislador constitucional passou outras orientações, por meio do artigo 216 da Constituição Federal, no sentido de que:

Constituem patrimônio cultural brasileiro os bens de natureza material e imaterial, tomados individualmente ou em conjunto, portadores de 
referência à identidade, à ação, à memória dos diferentes grupos formadores da sociedade brasileira, nos quais se incluem:

I - as formas de expressão;

II - os modos de criar, fazer e viver;

III - as criações científicas, artísticas e tecnológicas;

IV - as obras, objetos, documentos, edificações e demais espaços destinados às manifestações artístico-culturais;

$\mathrm{V}$ - os conjuntos urbanos e sítios de valor histórico, paisagístico, artístico, arqueológico, paleontológico, ecológico e científico (BRASIL, 2018, on line).

Nessa quadra de pensamento, a sociedade em rede, foi bastante impulsionada no período pandêmico, pelos motivos já expostos e, por esta razão, ganhou relevância e passou a influenciar não apenas o modo de criar e fazer de sua legião digital, como também operou mudanças em alguns segmentos da sociedade.

Desse modo, à disposição do internauta, existem diversas opções on line que praticamente o mantém em seu ambiente doméstico, que compreende o trabalho home office, compras remotas no comércio, operações em instituição bancária (inclusive por meio de criptomoedas ${ }^{6}$ ), participação interativa em aulas, reuniões ou eventos acadêmicocientíficos, consulta médica, bem como acesso, entrega e obtenção de documentos digitalizados em órgãos públicos ou entidades privadas, participar de leilões virtuais, aplicativos sociais ou de relacionamento, e até mesmo produzir ou assistir a shows artístico-culturais, por meio de lives, enfim, oferta-se um cardápio diversificado de opções eletrônicas.

A partir de tudo isso, o computador e a internet possibilitam o exercício da cidadania cultural (CAHAUÍ, 2006). Nesse ritmo, as limitações que a crise de saúde pública impuseram aos asilados surtiram um efeito diferente no universo digital, haja vista que alargou o cinturão virtual da sociedade em rede, dentro do qual os seus membros navegam e cujos métodos vêm influenciando os hábitos das pessoas, notadamente no campo artístico-cultural, matéria enfrentada adiante.

\footnotetext{
${ }^{6}$ Moeda digital, como o bitcoin.
} 


\section{DIVERSAS FORMAS DE MANIFESTAÇÃO POR MEIO DA WEB: UM DIREITO FUNDAMENTAL À SERVIÇO DA ARTE E DA CULTURA}

A visão concretizadora que se tem de arte e cultura, presentes na vida do homem, deve ser concebida pela sua capacidade de transmitir sentimentos, como uma correia propulsora, e não sob uma visão lógico-formal, por mais coerente que seja este olhar. Daí a relevância da implementação de políticas públicas que visem à inclusão digital, com vistas à redução da desigualdade social e ao desenvolvimento sustentável. Assim, além de concretizar o direito fundamental à cultura, estar-se-á incentivando o lazer como forma de promoção social, nos termos do $\S 3^{\circ}$, do artigo 217, da Constituição Federal.

Nesse passo, há variadas formas de manifestar os modos de criação, produção, difusão, distribuição e fruição das expressões artístico-culturais, seja qual for o meio ou a tecnologia empregada. De todo modo, não se deve graduar ou comparar a arte e a cultura desenvolvidas pelos homens, bem como a ambiência em que são apresentadas, visto que o importante é que sejam autênticas e promovam a cultura e o bem-estar de cada grupo social.

Na dimensão analisada, o meio virtual se consolidou como uma espécie de remédio à disposição da população, que ameniza as medidas restritivas, como o isolamento social, impostas nesse período pandêmico do coronavírus, e que mantém o ser humano conectado virtualmente às pessoas, ao trabalho, à diversão e, especialmente, à arte e à cultura.

No caso, a comunidade virtual, construída a partir da tecnologia de informação, retroalimenta-se através de um modelo de socialização criado na teia digital. É dizer, o ser humano sente a necessidade de expressar-se, o que representa uma opção para a libertação e a salvação de sua alma, oportunidade em que o conduz a novos estágios de vida.

E para se ter uma noção do avanço e importância da comunicação em massa desenvolvida no ambiente eletrônico, meio século depois da criação da internet, ocorrida na Califórnia (EUA), em 2019, apurou-se que 51\% da população mundial tem acesso à rede, de acordo com o relatório produzido pela Banda Larga das Nações Unidas (NOBERTO, 2019), e tudo isso favorece à conexão entre as pessoas, o compartilhamento de culturas e, por consequência, a movimentação de um grande fluxo de informações através das plataformas digitais. 
Ainda, para Castells (2006) a sociedade em rede se destaca como um importante instrumento midiático formador da opinião pública, constituída de receptores coletivos, cujas informações compartilhadas são repassadas de maneira célere, praticamente de forma instantânea, bem mais rápida que os meios tradicionais de comunicação (jornal, rádio, revista ou televisão). Logo, a força da comunicação transmitida virtualmente tem, igualmente, o condão de influenciar o pensamento das pessoas acerca de um determinado assunto.

Assim, a atividade artístico-cultural é desenvolvida de maneira multifacetada, por exemplo através de memes sobre obras, pessoas ou fatos antigos ou recentes. São ideias, espécies de caricatura digital que divertem todas as camadas do tecido social e que, por igual, exigem uma criatividade intelectual, com um pano de fundo sarcástico, portanto, integrante da cultura on line (SHIFMAN, 2014).

Sobre o assunto, Bruno Vaiano (2020) registrou que a palavra meme se originou da junção de mimeses, do grego que significa imitação, com o termo gene, cunhada primeiramente pelo biólogo Richard Dawkins, em 1976. No caso, a intenção do estudioso britânico foi batizar uma unidade de informação genética como uma plataforma de informação cultural.

Desse modo, as memes podem aparecer sob forma de frase, de uma imagem, de um vídeo ou link, que podem estar hospedados em sites ou blogs ou serem transmitidos por meio de mensagens e, sem dúvida, é um importante meio de comunicação e diversão entre os usuários de meios eletrônicos, notadamente sobre fatos que acontecem na humanidade.

Como a diversão compõe à vida humana, ou até mesmo se apresenta como uma necessidade para o bem-estar do ser humano, as memes, tipicamente desenvolvidas no ciberespaço, são muito aceitas e viralizam rápido na sociedade em rede, tanto que há sítios eletrônicos especializados na matéria. Cuida-se de uma manifestação artístico-cultural que representa fatos ou obras históricas ou do cotidiano, de maneira hilária, conforme ilustrado a seguir: 
Figura 1 - Meme sobre a obra Mona Lisa (A Gioconda)

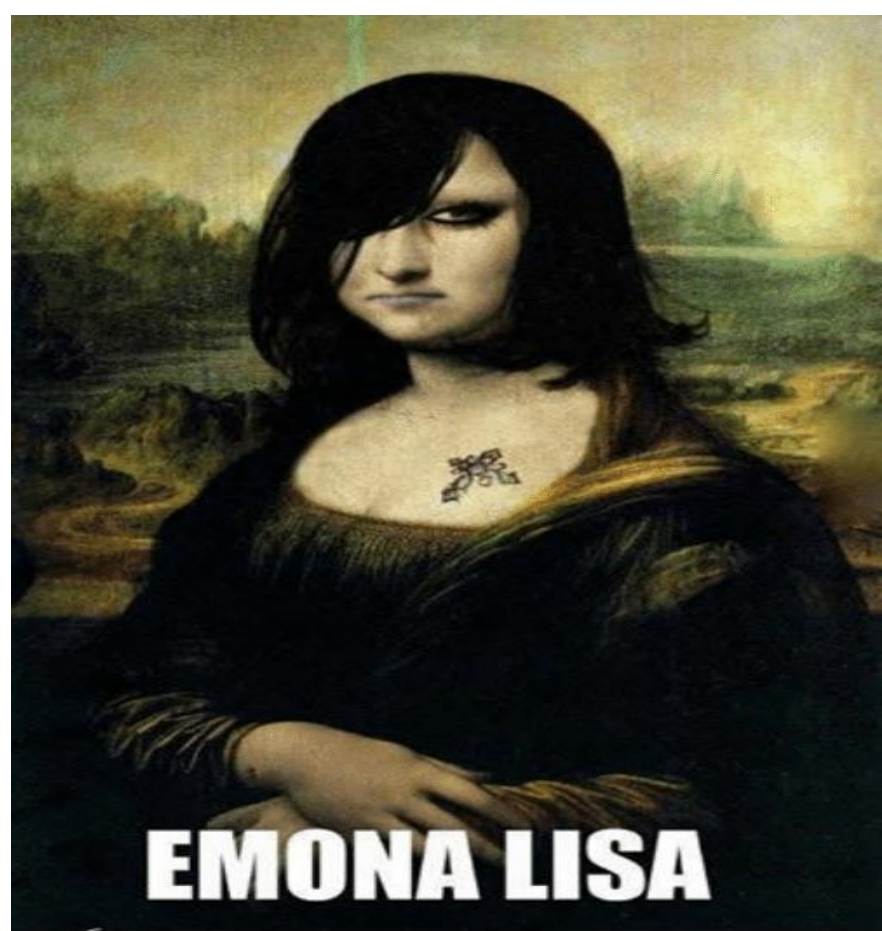

"Tell me why?"

"I don't like Mondays"

Fonte: https://me.me/i/classical-art-facebook-tell-me-why-i-dont-like-283609 (2016, on line).

Em relação aos acontecimentos verificados no período pandêmico pelo qual atravessa o país, Bichara (2020) expôs em matéria jornalística que a população brasileira é versátil e sabe conduzir, de forma humorada, as dificuldades sanitárias e financeiras provocadas pela COVID-19, como se observa à frente:

Figura 2 - Meme sobre as dificuldades enfrentadas no período pandêmico da COVID-19

\section{- Pai, o que aconteceu com o assento traseiro do carro? \\ - Tive que vender para comprar álcool em gel}

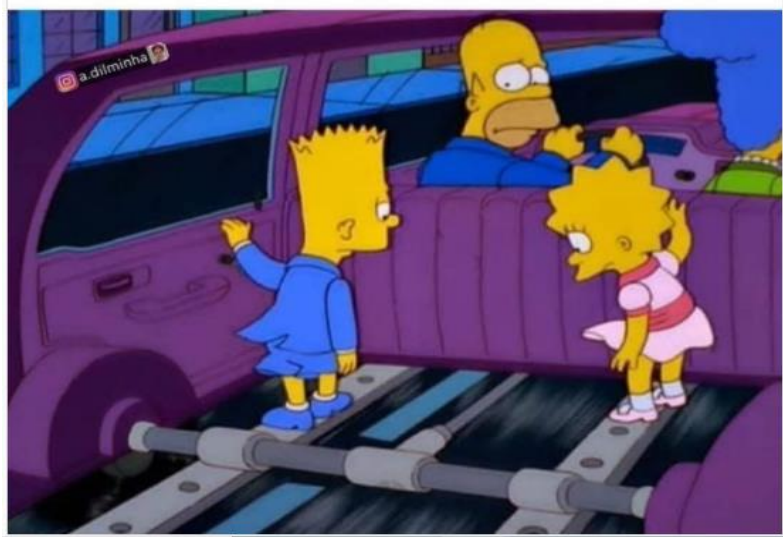

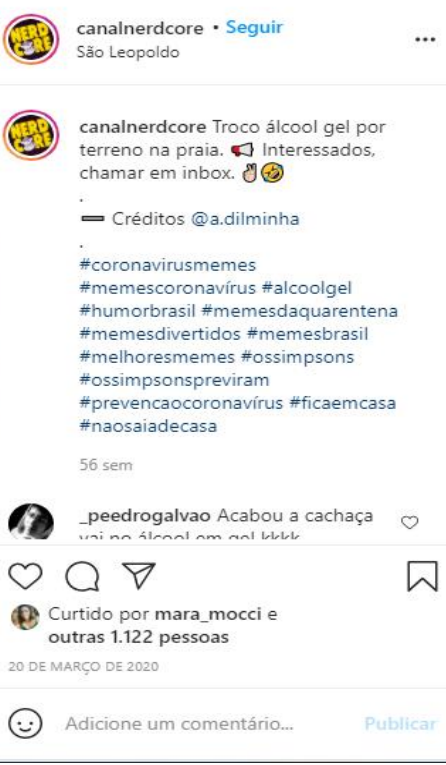

Fonte: https://www.agazeta.com.br/entretenimento/cultura/brasileiros-lidam-com-a-quarentenafazendo-memes-na-web-veja-alguns-0320 (BICHARA, 2020). 
Outro recurso terapêutico amplamente explorado na rede mundial, revelador da arte e da cultura, é a música, que contagia, encanta, ensina e poetiza a história, tudo à base da canção. Na hipótese, analisando as músicas de Chico Buarque, o professor Charles Perrone (1988, p. 40) pondera que a "busca da felicidade, a realização individual e coletiva, a fraternidade e a capacidade de transformação pessoal e social são poeticamente representadas e realizadas em muitas composições".

Hodiernamente, encontram-se diversas produções musicais na internet, inserindo-se os anônimos neste rol. Por esta razão, pode-se sustentar que a web democratizou a participação ativa e passiva em matéria musical. E nesse período pandêmico, multiplicaram-se as lives, com interações virtuais patrocinadas como forma de promover e monetizar os projetos artísticos (DINIZ, 2020).

De fato, as tecnologias de informação revelam as facetas de uma nova forma de democracia e cidadania cultural, haja vista que, tradicionalmente, os autores escrevem livros e o público os consome (DARCILIA, 2013), contudo a internet abriu notório espaço para manifestações artístico-culturais por meio de páginas eletrônicas, blogs, e-books (livros digitais) e até mesmo através de redes sociais (whatsapp, facebook e instagram) ou aplicativos de relacionamento (whatsapp, tinder e badoo), a partir dos quais um número notável de pessoas se expressam sobre assuntos do cotidiano, ou acerca de diversas matérias: arte, cultura, ciência, direito, educação, economia e política.

Sobre e-book, cuja produção aumentou consideravelmente durante o isolamento social, é uma empreendimento que vem se destacando no ambiente cibercultural, tanto que numa simples busca no google, encontra-se uma variedade de obras on line, gratuita e à disposição da sociedade em rede, como o livro digital: Para além da quarentena: reflexões sobre crise e pandemia (LOLE; STAMPA; GOMES, 2020), em que se aborda criticamente diversas questões a nível nacional e internacional sobre a COVID-19, inclusive acerca da crise do capitalismo e a situação da mulher, neste ciclo pandêmico.

Há ainda, no ambiente eletrônico, o Google Art \& Culture, programa que atua em cooperação com diversas instituições que promovem a arte e a cultura. Assim, os recursos artístico-virtuais oferecidos pelo mencionado aplicativo, de alta resolução (em gigapixels), permitem aos internautas que visitem, por meio da internet, as instituições que hospedam obras de arte e, assim, consigam visualizar, com clareza de detalhes, as obras, imagens e pinturas que nem sempre seriam percebidas presencialmente. 
E esta riqueza de minúcias, constatadas numa determinada obra artística, com apoio de recursos de tecnologia, constitui um plus ao conhecimento humano, na proporção em que se consegue extrair mais informações que são úteis à curiosidade do público, que eleva a sua compreensão acerca da mensagem artístico-cultural que se desejou repassar.

A respeito, depara-se com um exemplo perfeito das vantagens tecnológicas ofertadas pelo Google Art \& Culture, em dois momentos da mesma obra, em que pode ser visualizada nas Figuras 3 e 4 à frente, referente à gravura do pintor russo Alexander Andreyevich Ivanov, na sua arte sacra The Apparition of Christ to the People, concluída em 1857.

Figura 3 - Pintura da The Apparition of Christ to the People (The Apparition of the Messiah)

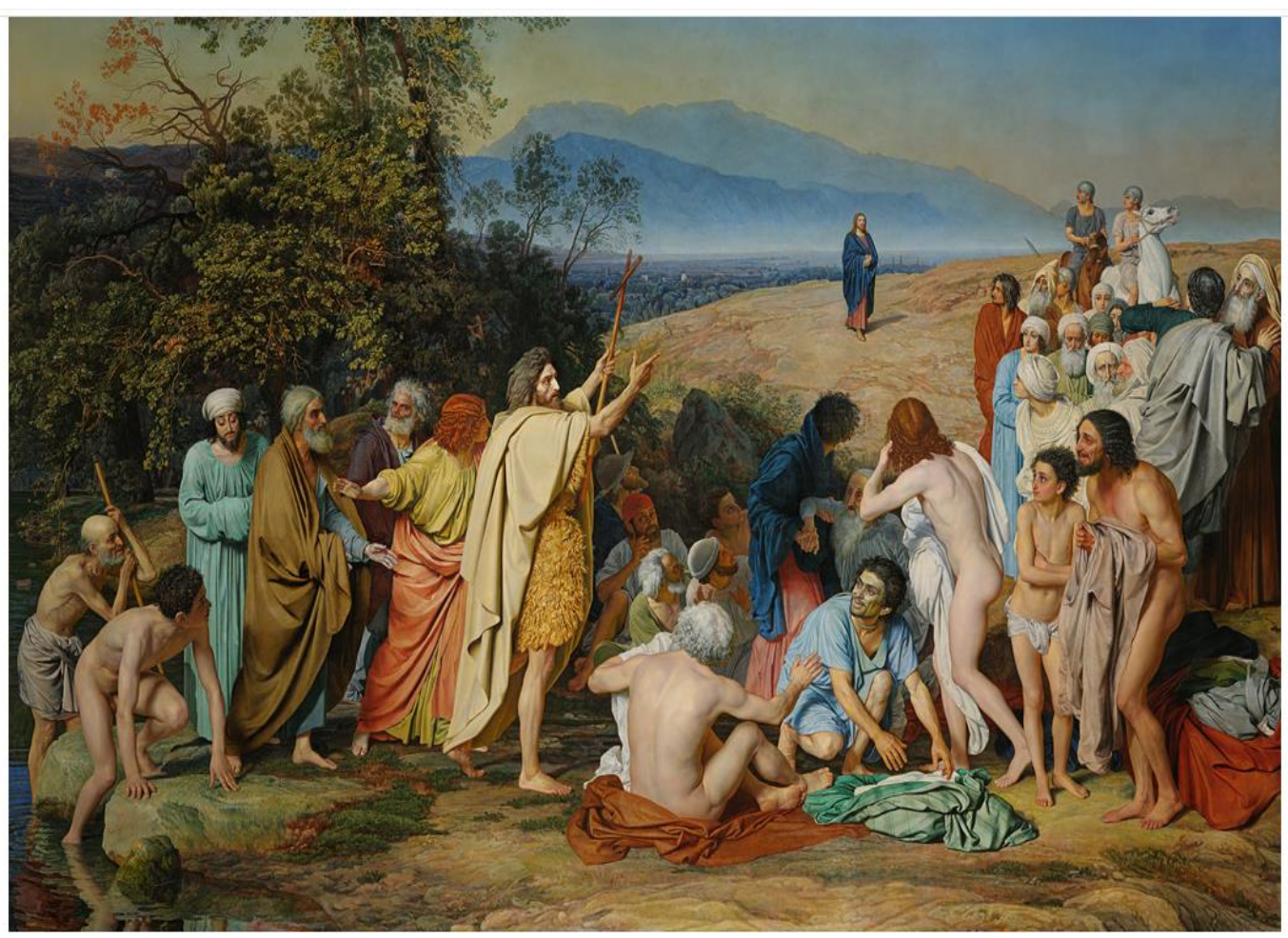

Fonte: https://artsandculture.google.com/asset/the-apparition-of-christ-to-the-people-theapparition-of-the-messiah/lgGqUffODe21kA (2021, on line).

Agora, note adiante (Figura 4), a mesma obra, que após ampliada com os recursos de informática ofertados pelo Googls Arts \& Culture, proporciona uma melhor visualização dos dotes artísticos do pintor, de maneira que são percebidas pessoas entre as árvores, inclusive com detalhes nos rostos, gestos e comportamentos dos cristãos, bem como vestimentas, detalhes nas folhas e galhos das árvores, dentre outras particularidades da pintura. 
Figura 4 - Imagem ampliada do quadro The Apparition of Christ to the People

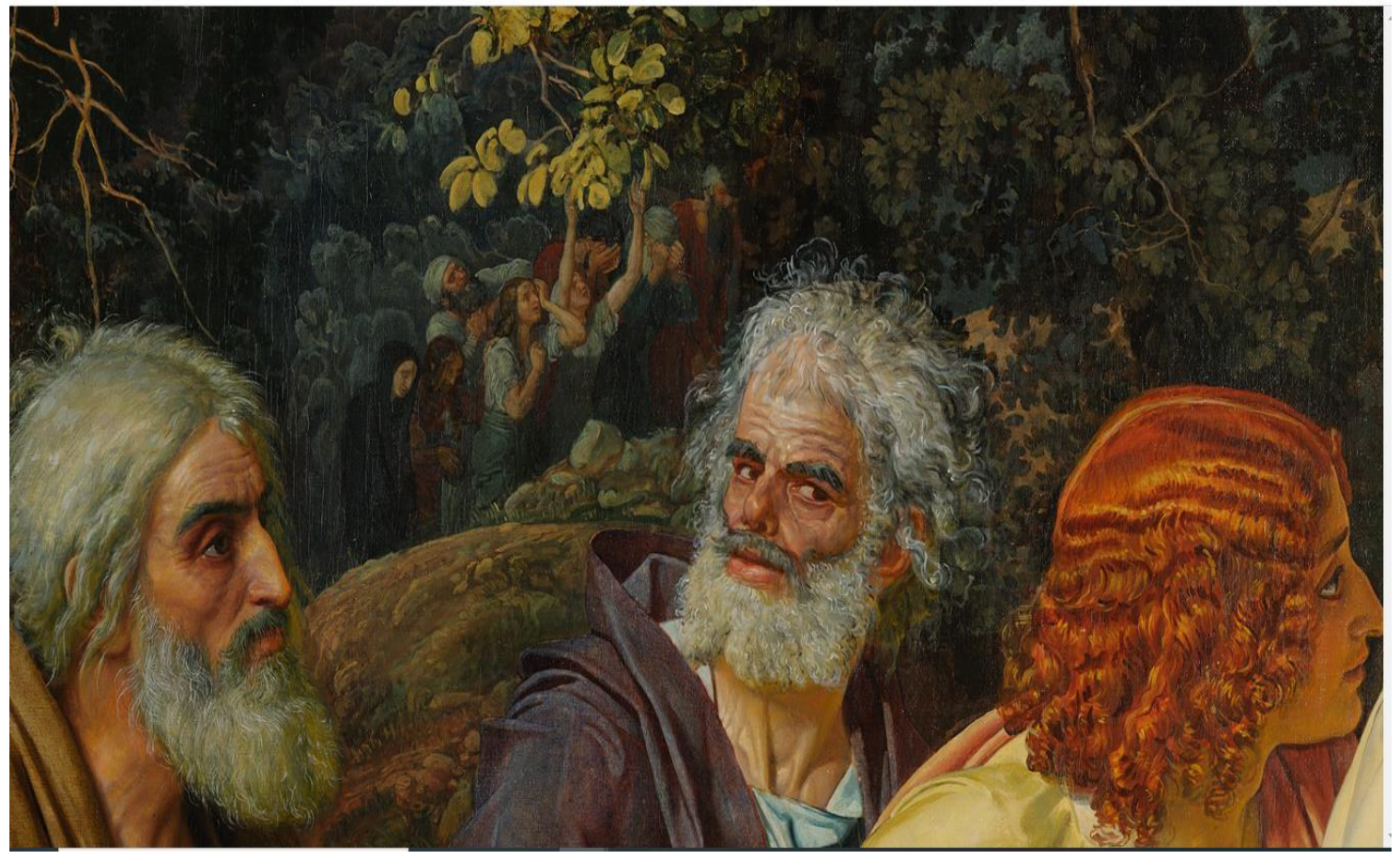

Fonte: https://artsandculture.google.com/asset/the-apparition-of-christ-to-the-people-theapparition-of-the-messiah/lgGqUffODe21kA (2021, on line).

Contudo, é relevante destacar que há pessoas que preferem a apreciação presencial de uma obra, considerando a magia do passeio cultural, tal como assistir a um filme no cinema ou visitar uma galeria de artes. Mesmo assim, não se pode olvidar que, durante o isolamento social imposto a bem da saúde pública, é possível manter-se atualizado com o mundo cultural sob um olhar e sentir virtual.

E para além da diversão, há outros recursos disponíveis à sociedade em rede que, de igual modo, agregam elementos artístico-culturais às iniciativas individuais ou coletivas, como a escrita virtual, assim entendida como a disponibilização, divulgação e compartilhamento de livros digitais ou digitalizados, artigos de revistas ou jornais, bem com pensamentos transformados em textos nos blogs, que expressam um sentimento ou repassam mensagens de conteúdo diverso.

Ainda na especificidade da matéria, interessante invocar a recente pesquisa do escritor Marco Haurélio, revelada por DINIZ (2021), no sentido de que a literatura de cordel, ainda que siga na sua impressão em folhetos, adaptou-se à era digital, meio século depois de sua existência, considerada no final do século XIX. Assim, mantém-se a tradição popular, especialmente dos nordestinos, que traz em seu âmago a crítica social sob o olhar dos cordelistas, com a presença ativa das mulheres na consolidação desse patrimônio cultural (DINIZ, 2021). 
Por tudo isso, procede a compreensão de que o direito fundamental à cultura expressado através de manifestações artístico-culturais, desenvolvidas nesta crise sanitária e postadas no mundo tecnológico, sob múltiplas formas: escritos (livros, obras, trabalhos acadêmicos), memes, músicas, notícias, pensamentos, pinturas e outras expressões virtuais, está à serviço da diversão do indivíduo e do desenvolvimento da humanidade, bem assim é um meio que atinge um público bem mais amplo, com maior rapidez e de maneira cômoda, sobretudo quando comparado com o modelo de divulgação pela imprensa tradicional, como jornal escrito, rádio e até mesmo a televisão.

\section{CONSIDERAÇÕES FINAIS}

As consequências sanitárias da COVID-19 provocaram, em benefício da saúde pública, a restrição de alguns direitos fundamentais dos cidadãos, como o direito de ir e vir, mas não o direito de manifestar-se, especialmente, por meio da sociedade em rede. Como resultado, foi percebido o aumento considerável de acesso de indivíduos à internet, até mesmo para acudir às suas necessidades de relacionamento social, manifestação do pensamento e da obtenção de informação, todos assegurados no Texto Constitucional de 1988.

Neste cenário, a sociedade informacional é constituída por toda a comunidade virtual que, na atual fase pandêmica, vem crescendo e se estabelecendo de forma globalizante, bem como influenciando pessoas e promovendo facilidades no modo de interagir, receber e transmitir informações entre quaisquer localidades abrangidas pela rede mundial de computadores.

E em razão da dinâmica do mundo digital, surge a cultura contemporânea virtual, batizada de cibercultura que, do ponto de vista do professor Saldanha (2017), representa uma manifestação que vai além das regras de conexão entre o comportamento do indivíduo e as novas tecnologias do mercado, visto que favorece a construção de novas formas de relacionamento social, independente de questões territoriais, com vistas a um novo modelo de compartilhamento, cooperação e processos abertos de informação e colaboração.

Demais disso, observou-se, durante a exposição neste artigo, que é bastante salutar a promoção da arte e da cultura digital como recurso terapêutico, bem assim como meio de desenvolvimento e inclusão social. Manifestações artístico-culturais, através da 
escrita, música, pintura, gestos e fala, expressadas na web, igualmente, são um instrumento de realização individual e coletiva, portanto, apresentam-se como ações que salvam e libertam a alma humana.

Ainda, diante do dinamismo da sociedade de informação, surgiu o chamado internetês, consistente no modo particular de se expressar na teia virtual, através de neologismos, terminologias e outras iniciativas diferenciadas da comunicação formal, revelando um ambiente aberto, plural e democrático, dentro do qual há espaço para todos, assim compreendidos os grupos sociais desfavorecidos, como negros, mulheres, índios, deficientes e comunidades LGBTQ+.

Porém, como uma realidade presente na vida de muitas pessoas, a internet é também palco da prática de fake news e crimes cibernéticos de diversas natureza (calúnia, injúria e difamação), cometidos geralmente por trás da tela (anonimato) e até mesmo com o fim de subverter a ordem jurídica, o regime democrático e a paz social.

Lado outro, estas ações maléficas não destroem a face benéfica ou positiva que o universo digital proporciona à humanidade, especialmente durante a crise provocada pelo agente Sars-Cov-2, causador do coronavírus, no meio da qual manteve virtualmente as pessoas, a educação, a ciência, a economia, a justiça, a política e, sobretudo, as manifestações artístico-culturais em movimento, ainda que de forma restrita e sem o contato pessoal ou presencial ao qual os humanos estão acostumados.

Em síntese, é patente a transformação que a sociedade em rede vem promovendo no modo de criar, fazer e viver da humanidade, particularmente na arte e na cultura digital, durante a fase pandêmica da COVID-19. Ainda, a importância da sociedade de informação é indiscutível, haja vista que a situação na qual se impôs o isolamento social, em que foi reduzido o contato das pessoas com o mundo exterior, afetou algumas necessidades do indivíduo, especialmente em relação à questão do relacionamento e da manifestação humana.

E todas essas transformações ocorridas na fase pandêmica leva ao entendimento de que, caso não houvessem as benesses da sociedade em rede, haveria sérias consequências, sobretudo de ordem pessoal e social, frente à necessidade do homem em relacionar-se com o próximo, ainda que de maneira virtual. 


\section{REFERÊNCIAS}

BICHARA, Sarah. Brasileiros lidam com a quarentena fazendo memes na web; veja alguns: as postagens modificam imagem de séries e filmes para fazer humor e aliviar a tensão da pandemia. 2020. A Gazeta. Disponível em: https://www.agazeta.com.br/entretenimento/cultura/brasileiros-lidam-com-aquarentena-fazendo-memes-na-web-veja-alguns-0320. Acesso em: 16 abr. 2021.

BRASIL. Supremo Tribunal Federal (STF). A Constituição e o Supremo. Supremo Tribunal Federal. 6. ed. atual. até a EC 99/2017. Brasília: STF, Secretaria de Documentação, 2018. Disponível em http://www.stf.jus.br/portal/constituicao/constituicao.asp\#1940. Acesso em 20 mai. 2021.

BRASIL. Decreto 6.177, de 1 de agosto de 2007. Promulga a Convenção sobre a Proteção e Promoção da Diversidade das Expressões Culturais, assinada em Paris, em 20 de outubro de 2005. DOU. Brasília/DF, 2 ago. 2007. Disponível em: http://www.planalto.gov.br/ccivil_03/_ato2007-2010/2007/decreto/d6177.htm. Acesso em 20 mai. 2021.

BRASIL. Lei 12.965, de 23 de abril de 2014. Estabelece princípios, garantias, direitos e deveres para o uso da Internet no Brasil. DOU. Brasília/DF, 24 abr. 2014. Disponível em: http://www.planalto.gov.br/ccivil_03/_ato2011-2014/2014/lei/112965.htm. Acesso em 20 mai. 2021.

CASTELLIS, Manuel. A sociedade em rede. A era da informação: economia, sociedade e cultura. V. 1. Lisboa: Fundação Calouste Gulbenkian, 2002.

CASTELLIS, Manuel. A sociedade em rede. 9 ed. São Paulo: Paz e Terra, 2006.

CHADE, Jamil. PIB, comércio e indicadores sociais confirmam maior crise em gerações. 2020. Matéria jornalística publicada no UOL, em 13/05/2020. Disponível em: https://noticias.uol.com.br/colunas/jamil-chade/2020/05/13/raio-X-do-mundo-napandemia-revela-maior-crise-em-geracoes.htm. Acesso em: 12 abr. 2021.

MARILENA, Chauí. Cidadania cultural: o direito à cultura. São Paulo: Fundação Perseu Abramo, 2006.

CUNHA FILHO, Francisco Humberto. Teoria dos direitos culturais: fundamentos e finalidades. São Paulo: Edições Sesc São Paulo, 2018.

DARCILIA, M. P. Simões (org.). Semiótica, Linguística e Tecnologias de Linguagem. Homenagem a Umberto Eco. Rio de Janeiro: Dialogarts, 2013. 
DINIZ, Pedro. Lives com interações virtuais patrocinadas são nova tentativa de monetizar projetos artísticos: pandemia forçou marcas e artísticas a encontrarem alternativas para atingir o público. 2020. Folha de São Paulo. Disponível em: https://www1.folha.uol.com.br/seminariosfolha/2020/12/lives-com-interacoes-virtuaispatrocinadas-sao-nova-tentativa-de-monetizar-projetos-artisticos.shtml. Acesso em: 16 abr. 2021.

DINIZ, Augusto. Cordel se adaptou à era digital, mas folheto impresso segue soberano: autor e pesquisador Marco Haurélio conta como anda hoje a tradição popular, depois de mais de um século de existência. Autor e pesquisador Marco Haurélio conta como anda hoje a tradição popular, depois de mais de um século de existência. 2021. Publicado na revista Carta Capital. Disponível em:

https://www.cartacapital.com.br/carta-capital/cordel-se-adaptou-a-era-digital-masfolheto-impresso-segue-soberano/. Acesso em: 24 abr. 2021.

GOMES, Mércio Pereira. Antropologia: ciência do homem, filosofia da cultura. São Paulo: Contexto, 2014

LOLE, Ana; STAMPA, Inez; GOMES, Rodrigo Lima Ribeiro (org.). Para além da quarentena: reflexões sobre crise e pandemia. Rio de Janeiro: Mórula Editorial, 2020. Disponível em: https://morula.com.br/wpcontent/uploads/2020/06/ParaAlemDaQuarentena.pdf. Acesso em: 15 abr. 2021.

MARILENA, Chauí. Cidadania cultural: o direito à cultura. São Paulo: Fundação Perseu Abramo, 2006.

NOBERTO, Cristiane; LOIOLA, Catarina. $51 \%$ da população mundial têm acesso à internet, mostra estudo da ONU. 2019. Jornal Correio Braziliense. Disponível em: https://www.correiobraziliense.com.br/app/noticia/economia/2019/11/04/internas_econ omia,803503/51-da-populacao-mundial-tem-acesso-a-internet-mostra-estudo-daonu.shtml. Acesso em: 10 abr. 2021.

PERRONE, Charles A. Letras e letras da música popular brasileira. Rio de Janeiro: Elo Editora, 1988.

SALDANHA, Alexandre Henrique Tavares. Direitos autorais, liberdade de expressão e cultura de participação na internet. Direitos Culturais, Santo Ângelo, v. 12, n. 27, p. 33-46, maio/ago. 2017.

SHIFMAN, Limor. Memes in a digital culture. Cambridge: MIT, 2014.

TOLSTOI, Leon. O que é a arte? São Paulo: editora Ediouro, 2002.

TOLSTOI, Leon. O que é arte? In: Os últimos dias. São Paulo: Penguin-Companhia das Letras, 2011. 
VAIANO, Bruno. Qual é a origem da palavra "meme"? 2020. Elaborado pela Super Interessante, do Grupo Abril. Disponível em: https://super.abril.com.br/blog/oraculo/deonde-surgiu-a-palavra-meme/. Acesso em: 15 maio 2021.

Recebido em: 20/10/2021

Aprovado em: 23/11/2021

Publicado em: 25/112021 